\title{
Gender and Transaction Costs in Use of Zero Grazing Net for Tsetse Fly and Trypanosomiasis Control in Stall Feeding Systems in Kenya
}

\author{
Jared Isaboke Mose ${ }^{1}$ \\ ${ }^{1}$ Department of Agricultural Economics and Resource Management, Moi University, Kenya \\ Correspondence: Jared Isaboke Mose, Department of Agricultural Economics and Resource Management, Moi \\ University, Kenya. E-mail: mosejared@yahoo.com
}

Received: August 13, 2017

Accepted: September 21, 2017 Online Published: September 29, 2017

doi:10.5539/enrr.v7n3p96

URL: https://doi.org/10.5539/enrr.v7n3p96

\begin{abstract}
Trypanosomiasis is a widespread constraint in livestock production, mixed farming and human health in Africa. Several technologies have been developed to ameliorate the effects of the disease but delivery of these technologies to farmers has been undertaken on trial and error basis without a proper strategy leading to more failure than success and wastage of scarce resources. The purpose of this paper was to carry out an analysis of transaction costs incurred in accessing and using insecticide treated net in tsetse and trypanosomiasis control among smallholder cattle farms in Busia County, Kenya. The study utilized cross-sectional survey design and was guided by the New Institutional Economics approach and utilized stratified and simple random sampling technique to get 211 respondents for the study. Data was collected by use of structured questionnaires and analyzed using descriptive and inferential statistics. Conjoint analysis results for zero grazing net showed that cost was the most important factor influencing farmers' decision, accounting for $38.52 \%$ of the total while durability and availability each accounted for $25 \%$ and retreatability accounted for $10 \%$ of the decisions. Further t-test results showed that there were significant differences between men and women with respect to attribute scores (at 99 d.f. and alpha $=0.05 \%$ ) suggesting that men and women face different transaction costs in accessing T\&T control technologies. Therefore there is need for gender sensitive strategies in T\&T technology design and dissemination. Tsetse fly and Trypanosomiasis control by use of low cost technologies such as insecticide treated zero grazing net should be promoted by government and other development partners. The net should be affordable, available at supply outlets close to farmers, long lasting and re-treatable for famers to take it up.
\end{abstract}

Keywords: Trypanosomiasis, zero grazing net, transaction costs, conjoint analysis, gender

\section{Introduction}

Trypanosomiasis is one of the most economically important diseases of man and livestock in Africa (GOK, 2011). Tsetse flies (Glossina species) infest 37 African countries covering an area of approximately 11 million square kilometers. In Kenya, the coverage is about 138,000 square kilometers, which is approximately $23 \%$ of the country and in 38 out of 47 counties (see map in appendix I). The social and economic consequences of Tsetse and Trypanosomiasis (T\&T) are serious with losses in livestock and agricultural productivity in Africa estimated at US $\$ 1.3$ billion a year $(\mathrm{GOK}, 2011)$. The animal resource industry in Kenya is estimated at Kenya Shillings 250 billion worth with T\&T infestation leading to $20 \%$ drop in productivity. One can estimate annual losses of between Ksh 20 to Ksh 50 billion attributable to livestock disease especially trypanosomiasis based on epidemiological trends.

The potential of human sleeping sickness outbreak recurring is high in the Lake Victoria basin region and other high risk areas with nearly 11 million people at risk (GOK, 2011). The disease is fatal with high costs of medication with accompanying losses in manpower negatively affecting the economy. Economic loses attributed to tsetse and trypanosomiasis is through the following: cost of treatment to humans and livestock, mortality of infected animals and loss of human lives, unproductive sick people, abortion, loss of milk, loss of animal draught power and inability to plough at all in certain areas, inability to graze in certain areas, the inability to market livestock, or lower prices obtained for trypanosomiasis affected animals and poor body conditions making animals unsuitable for slaughter for meat, loss of foreign exchange through imports of drugs and lost opportunity to export livestock and livestock products (GOK, 2011). 
Tsetse and trypanosomiasis control has been seen as a public good in Kenya, in which the government shoulders the burden of prevention, eradication and treatment. Efforts by the Government of Kenya and development partners have led to a number of programs aimed at tsetse control. Research has been undertaken by the Kenya Trypanosomiasis Research Institute (KETRI, now part of KARLO, the Kenya Agricultural and livestock Research Organization), ICIPE (International Centre for Insect Physiology and Ecology), and ILRI (International Livestock Research Institute) in collaboration with the Veterinary Department. Projects under the OAU - IBAR have been undertaken in western Kenya namely: Farming in Tsetse Controlled Areas (FITCA) and Pan African Tsetse and Trypanosomiasis Eradication Campaign (PATTEC).

Under these projects Tsetse control methods targeting individual households and small communities/groups have been promoted. These include insecticide treated nets for zero grazing units, spraying livestock with insecticide in community crush pens in addition to the traditional methods - targets and traps, bush clearing and bush spraying. However, it is unclear whether these control methods, used in combination, will continue to be applied after the end of the project period, and whether there is any coordination between different control methods. Therefore, it is important for small scale, cost effective methods to be adopted by diverse farmers, so as to ease the cost burden on donors and the Government.

While it is recognized that tsetse control is a public good, in the livestock industry it can be seen increasingly as a private investment where the end users play an active role in management of the tsetse control activities. Eschessah et al. (1997) recognize that community participation has become one of the basic elements of governments' policies and programs for tsetse control. It is recognized that local participation in rural development is desirable for sustainability and in the hope that some of the costs can be handed over to the community. Thus all that is needed is a proper monitoring and coordination structure to ensure that there is no duplication of effort at small scale level in managing trypanosomiasis. On the other hand, this should also ensure that there are no gaps in implementation due to the diverse nature of activities needed to manage trypanosomiasis.

Currently, the promotion of various technologies for adoption by farmers is being undertaken on ad hoc basis. This has raised questions with regard to sustainability of several trypanosomiasis control programs initiated in various parts of the country. There is limited information on small holder farmers' preferences for alternative trypanosomiasis control technologies in different livestock production systems in Kenya and Busia County in particular. Therefore, information on farmer's preferences for alternative trypanosomiasis control technologies, determinants for these preferences and the transaction costs involved in accessing these technologies will form a basis for developing a dissemination and implementation strategy for these technologies. This paper aims at availing information for design of better T\&T control strategies. It is envisaged that the strategy to be developed from information arising from this study will include but not be limited to undertaking farmer education about these technologies and also determining measures that may need to be put in place to facilitate up-take of these technologies. The main objective of this study was to analyze the transaction costs incurred in accessing zero grazing net in T\&T control.

The rest of the paper is organized as follows. Section 2 describes the theoretical framework. Section 3 discusses the study design. Section 4 presents the study findings and discussion and section 5 concludes.

\section{Theoretical Framework}

New Institutional Economics (NIE) approach was applied in identifying and categorizing the transaction costs farmers faced in accessing and using communal crushpen. In neo-classical economic theory, a product or service is assumed to be available to all market participants, at a price determined by forces of supply and demand. These prices in turn determine the behavior of market participants in making their production decisions, as well as consumers in making their consumption decisions. The NIE has however recognized that market participants not only face these market prices, but also additional costs associated with arranging market transactions (Nabli \& Nunget, 1989; Hubbard, 1997). Existence of high transaction costs may result in market failure that is, eliminating the possibility of an exchange taking place.

Despite the fact that a standard classification for transaction costs is yet to be agreed upon, Randolph and Ndun'gu (2000) have broadly categorized them as: (i) information costs - costs encountered prior to the transaction and include those related to searching for and screening potential trading partners and obtaining price information; (ii) negotiation costs - costs encountered during the transaction and entail expenses related to arranging the trade, physically transferring the product or service and drawing up contracts; and (iii) enforcement costs - costs encountered after the transaction and are related to monitoring the terms of trade and enforcing liability. 
The difficulties in characterizing many types of transaction costs explains to a large extent the little progress made with respect to their empirical measurement (Randolph \& Ndun'gu, 2000). Staal et al. (1997) further notes that besides transactions costs being difficult to quantify, in many cases, the prohibitive costs are simply not observable in cases where they are quite high to cause market failure. This concept of NIE was applied in identifying and categorizing the different transaction costs faced by farmers in accessing trypanosomiasis control technologies.

After identifying and categorising the important transaction costs, a conjoint analysis is used to quantify the importance of each category of transaction costs. The conceptual foundation of conjoint analysis is based on the consumer theory as developed by Lancaster $(1966,1991)$. This theory assumes that utility is derived from the properties or characteristics of goods (Ratchford, 1975). A major implication is that the overall utility for a good can be decomposed into separate utilities for its constituent characteristics or benefits (Louviere, 1994). In terms of the utility function, this translates into using the characteristics of goods as the arguments of the function. Conjoint analysis provides a suitable empirical application of the Lancaster consumer theory (Rosen, 1974; Griliches, 1971).

Conjoint analysis is a multivariate technique that is specifically used to understand how respondents develop preferences for products or services (Green \& Srinivasan, 1978). It is premised on the argument that consumers evaluate the value or cost of a product, a service or an idea, whether real or hypothetical, by combining the separate amounts of values or costs provided by or attached to each attribute (also known as factor). Each product is conceived to be made up of a combination of different factors, and each of these factors exists at different levels in any given product. When used to evaluate the preference/choice of a product, the conjoint analytical approach assumes that utility is based on the value placed on each of the levels of factors and is expressed in a relationship that is reflective of the manner in which the utility is formulated for any combination of factors. Similarly, the cost of a product or service is derived on the individual 'costs' of different levels of factors making up the product or service. Based on this argument, it is then assumed that products, services or ideas with higher utility values are more preferred and have better chances of being chosen.

The operationalization of the conjoint analysis entails constructing specific combinations of factors (also known as stimuli). The objective is to attempt to understand a respondent's preference structure. This preference structure explains both the importance of each factor in the overall decision and how differing levels within a factor influence the formation of an overall preference/utility Green and Srinivasan, (1990). This utility is taken to represent the "total worth" of a product, and it is taken to be based on the "part-worth" of each level. The conjoint model is therefore expressed as:

$$
T_{i j \ldots . n m=} P_{i 1}+P_{j 2}+\cdots+P_{n m} \cdots
$$

Where:

$\mathrm{T}_{\mathrm{ij} \ldots \mathrm{nm}}=$ is the total worth for the product, service or idea that has $m$ factors, each having $n$ levels. Specifically, the product specified consists of level $i$ of factor 1 , level $j$ of factor 2 , and so on, up to level $n$ for factor $m$.

$\mathrm{P}_{\mathrm{i} 1}=$ is the part-worth of level $i$ for factor 1

$\mathrm{P}_{\mathrm{j} 2}=$ is the part-worth of level $j$ for factor 2

$\mathrm{P}_{\mathrm{nm}}=$ is the part-worth of level $n$ for factor $m$.

In this study analysis of the conjoint ranking was done to decompose farmers' ranking of the various combinations to estimate the proportional contribution, or "part-worth", of each attribute level to the "total -worth" expressed in the ordinal ranking of the combinations. The part-worth values were useful in describing the farmer's preferences across the identified attribute levels. They were important in estimating the 'usefulness score' for each attribute, was the relative importance of the attribute in percentage terms in the farmer's decision-making (with the usefulness scores for all other attributes summing to 100). The conjoint analysis was performed for the whole sample and the results evaluated using the non-parametric rank correlation measures Kendall's $\tau$.

\section{Study Design}

A cross -sectional survey was adopted in this study. This approach was preferred because it is efficient in collecting large amounts of information within a short time. Kerlinger (2003) argues for the use of surveys in socio-economic fact finding because they provide a great deal of information which is accurate. Furthermore, 
Cohen and Manion (2003) state that the intention of a survey is to gather data at a particular point in time and use it to describe the nature of existing conditions. Cross-sectional surveys usually relate to the present state of affairs and involve an attempt to provide a snapshot of how things are at a specific time at which the data is collected (Fraenkel \& Wallen, 2000). It is often characterized by the selection of random samples from large populations to obtain empirical knowledge of a contemporary nature (Saunders et al., 2007). Past research has tended to focus exclusively on knowledge production from an analytical-empirical perspective, using traditional quantitative methods associated with the dominant scientific paradigm (Mtshali, 2002). However, a possible integration of research methods, based on either simultaneous or sequential mixing of quantitative and qualitative values and techniques, is perhaps the best avenue to find the answers to questions posed, and being influenced by Farming Systems Research (FSR) (Barrett, 2004). The approach used in this study was geared towards discovery of new information while at the same time testing the study hypotheses. Leedy (1993) observed that nothing comes out at the end of a long and involving study that is any better than the care and the careful selection of the population.

The study was conducted in Busia County which is at the most westerly part of Kenya. Busia County was purposively selected because it is a tsetse endemic region and livestock production is an important economic activity. The T\&T problem is a serious obstacle to human settlement and livestock development in the County. T\&T control programs have been undertaken in the County by the Kenyan government together with other development partners. The study targeted zero grazing and semi-zero grazing cattle's farmers in Busia County. The County consists of seven administrative districts namely: Busia, Nambale, Butula, Bunyala, Samia, Teso North and Teso South. The County borders the Republic of Uganda on the West and Siaya County on the South. In the North lies Bungoma County while the East border is shared between Bungoma and Kakamega Counties. The Southern tip of Busia County borders Lake Victoria and Siaya County (see appendix II). It covers a total area of 1695 square kilometers with a population of 743,946 people. The main economic activity is trade with neighboring Uganda, with Busia Town and Malaba being cross-border centers. Away from town, the district economy is heavily reliant on fishing and agriculture, with cassava, millet, sweet potatoes, beans, and maize being the principal cash crops. Though most residents of Busia County are ethnically Luhya and Iteso there is also a substantial population of Luo and Kisii residents. The poverty rate is $66.7 \%$. Majority of the residents are rural with only $16.4 \%$ living in urban areas. The highest points in this area are at about $1500 \mathrm{~m}$ above sea level, located in Samia and Teso hills. The county is comprised of lower midland (LM) agro-ecological zones. These include LM1, LM2, LM3 and LM4. The wetter LM1 lies in the middle in Busia/Nambale while the LM4 is found in the extreme south in Bunyala. To the extreme north in Teso is LM3. It receives between 1270 $1790 \mathrm{~mm}$ of rainfall annually with slight spatial variation (Jaetzold \& Schmidt, 1983). The rainfall amount generally decreases from north to south with a reliability of more than $66 \%$. The maximum monthly rainfall falls between April and May. The county is characterized by undulating terrain intersected by numerous valleys. Soils are generally shallow to moderately deep (up to $50-80 \mathrm{~cm}$ ), and have low fertility. Soils on hills are generally shallow with rock outcrop. These soils require organic and inorganic fertilizers application in order to sustain crop production. The County falls in the sugarcane-belt, with maize and cotton production being important enterprises. Cattle farming is undertaken with dairying gaining importance. Cattle are also used for draft power (Jaetzold \& Schmidt, 1983). Cattle breeds kept include local Zebu and improved dairy of various crosses (Friesian, Ayrshire, and Guernsey).

This study used probability sampling procedure, following Saunders et al. (2007), to determine a sample size of 217 cattle farmers used in the study. The sampling of farmers was based on the prevailing dairy production systems which in this study were zero grazing and semi-zero grazing. A list of all zero grazing farmers in the County was constructed with the assistance of Ministry of Livestock Development Extension Staff and local leaders. Based on this list, farmers were selected using a random procedure. Overall, 101 households were selected from the zero grazing group. Selection of semi-zero grazing farmers was based on the communal spraying crush pens. A list of all the crush pens was obtained from the Veterinary Department. The local Animal Health Assistants and crush pen leaders assisted in identifying all participating households in the study area. This list was used as a sampling frame from which a random sample of 110 semi-zero grazing households was drawn.

Primary data was obtained directly from zero-grazing and semi-zero grazing cattle farmers through questionnaires. Types of data included general demographics of the respondents such personal characteristics of the household head (age, education), farm-specific characteristics (number and class of livestock owned, major livestock diseases, types of crops grown and their acreage) and the nature and sources of trypanosomiasis control technologies in particular and veterinary services in general utilized in the area (type of trypanosomiasis control technologies, frequency of use of these technologies, preference for particular technologies). 
The main data collection instrument for the study was questionnaire. The questions were subdivided into sections to capture the response and details that were required. The questions included closed and open ended questions; fill in questions and questions that required ranking of answers. The questions were stated clearly, simplified and structured in a manner devoid of any ambiguity and technical details.

In order to collect information on transaction costs, cards were generated using SPSS software. An orthogonal design of 20 cards including four holdouts was generated. Since the zero grazing net was being popularized for zero grazing the experiment involved ranking cards representing various zero grazing nets. The nets were similarly represented using drawings, short descriptions and figures. Card list used is given in appendix III and sample card in appendix VI.

\section{Results and Discussion}

The results of conjoint analysis for zero grazing net are reported in table 1. For attributes with only two levels or with linear relationship assumed, the standard deviation was the same at all levels. The attributes having three levels display fairly linear relationship across the three levels. Mean part-worths are also reported in table 1 for men and women respondents. Men and women exhibited remarkably similar part-worths across all attributes and individual attribute levels. The measures of correlation between the actual and predicted rankings were very high indicating good model fit. Correlations for the four holdouts showed that, on average the predicted rankings for the four holdout combinations correctly matched the farmers' actual rankings. Based on the part-worths, the relative importance of each attribute in determining the 16 orthogonal combinations was estimated. The relative importance scores were percentages that sum to $100 \%$ over the four attributes. The score indicates the share of the overall ranking decision attributable to a given attribute, and thus serves as an indicator of its role in the decision making process. The results are presented in table 2 .

Table 1. Mean Part-Worth Scores for Zero-Grazing Net

\begin{tabular}{|c|c|c|c|c|c|c|}
\hline \multirow{2}{*}{ Attributes } & \multicolumn{2}{|c|}{ Women } & \multicolumn{2}{|l|}{ Men } & \multicolumn{2}{|c|}{ Full sample } \\
\hline & Utility Estimate & Std. Error & Utility Estimate & Std Error & Utility Estimate & Std. Error \\
\hline \multicolumn{7}{|l|}{ 1. Cost } \\
\hline Low & .155 & .586 & .340 & .403 & .296 & .412 \\
\hline Medium & 2.109 & .703 & .761 & .483 & 1.081 & .494 \\
\hline High & -2.264 & .695 & -1.101 & .477 & -1.377 & .488 \\
\hline \multicolumn{7}{|l|}{ 2. Availability } \\
\hline Near & 1.067 & .450 & .750 & .309 & .825 & .317 \\
\hline Far & -1.067 & .450 & -.750 & .309 & -.825 & .317 \\
\hline \multicolumn{7}{|l|}{ 3. Durability } \\
\hline 1 Year & -.724 & .606 & -.174 & .416 & -.305 & .426 \\
\hline Two Years & -1.335 & .640 & -.449 & .440 & -.659 & .450 \\
\hline Over 3 Years & 2.058 & .729 & .623 & .501 & .964 & .513 \\
\hline \multicolumn{7}{|l|}{ 4. Retreatability } \\
\hline Re-treatable & -.275 & .450 & -.341 & .309 & -.325 & .317 \\
\hline Not Re-treatable & .275 & .450 & .341 & .309 & .325 & .317 \\
\hline (Constant) & 10.840 & .487 & 10.516 & .334 & 10.593 & .342 \\
\hline Rank correlations for overall sample & Value & Sig. & & & & \\
\hline Pearson's R & .968 & .000 & & & & \\
\hline Kendall's tau & .982 & .000 & & & & \\
\hline For 4 holdouts Kendall's tau & 1.00 & .000 & & & & \\
\hline
\end{tabular}

Source: Survey Data

Cost was the most important factor influencing farmers' decision, accounting for $38.52 \%$ of the total on average. Durability and availability each accounted for $25 \%$ of the decision while retreatability accounted for $10 \%$ of the decisions. 
Table 2. Mean Relative Importance Scores (Percentages)

\begin{tabular}{lccc}
\hline Attributes & Women & Men & Full sample \\
\hline 1. Cost & 41.845 & 36.404 & 38.521 \\
2. Availability & 20.420 & 29.320 & 25.857 \\
3. Durability & 32.466 & 20.955 & 25.434 \\
4. Retreatability & 5.270 & 13.321 & 10.188 \\
TOTAL & $\mathbf{1 0 0 . 0 0}$ & $\mathbf{1 0 0 . 0 0}$ & $\mathbf{1 0 0 . 0}$ \\
\hline
\end{tabular}

Source: Survey Data.

The results clearly show that farmers considered other attributes besides price in choosing a zero grazing net. The most important attribute underlying farmers' decision was price which is in line with the traditional consumer theory. Availability which was captured as distance accounted for $25 \%$. Distance is an important factor since travel time has opportunity cost in terms of valuable work lost besides the more direct cost of travelling. Distance was a useful proxy for a number of transaction costs such as transportation, time opportunity costs and access to service information. The results confirm studies by Woods (2000) who examined the effects of distance and gender in the utilization of veterinary services in Zimbabwe and concluded that travel time and transport were negatively related to the use of services. Oruko (1999) found distance inconsistently significant in the demand for veterinary services in two districts of Kenya. Durability accounts for $25 \%$ showing that farmers consider replacement costs as a constraint. The least important factor was retreatability. The results indicate that design and dissemination of insecticide treated zero grazing net for T\&T control should take into account cost, availability, durability, and re-treatability. The net should affordable, available at supply outlets close to farmers long lasting and re-treatable for famers to take it up. A t-test was used to find whether there were significant differences between men and women with respect to attribute scores. Results in table 3 show that at (99 d.f. and alpha $=0.05 \%$ ) there were significant differences between men and women in the relative importance scores.

Table 3. Comparison of Means between Men and Women -Zero Grazing Net

\begin{tabular}{lcc}
\hline Attribute & t- calculated & t-tabulated \\
\hline 1. Cost & 11.709 & 1.9842 \\
2. Availability & 28.076 & 1.9842 \\
3. Durability & 24.862 & 1.9842 \\
4. Retreatability & 25.397 & 1.9842 \\
\hline
\end{tabular}

Source: Survey Data.

This implies that men and women face different transaction costs in accessing T\&T control technologies. Therefore there is need for gender sensitive strategies in T\&T technology design and dissemination.

\section{Conclusions}

Conjoint results showed that cost, durability, availability and retreatability were important factors influencing farmers' choice of a zero grazing net. The results provide evidence that transaction costs play an important role in farmers' choice of a zero grazing net. On gender basis, it was found that there were significant differences in transaction costs faced by men and women in accessing T\&T control technologies.

\section{References}

Barret, J. C. (1997). Economic issues in Trypanosomiasis control. NRI Bulletin 75. Chatham U.K.: Natural Resources Institute.

Cohen, L., \& Manion, C. (2003). Research Methods in Education. London Croom Ltd.

Echessah, P. N., Swallow, B. N., Kamara, D. W., \& Curry, J. J. (1997). Willingness to contribute labour and money to tsetse control: Application of Contingent valuation in Busia District, Kenya. World Development, 25(2), 239-253.

Fraenkel, J. R., \& Wallen, N. E. (2000). How to design and evaluate research in Education. London, U.K: McGraw Hill. 
GOK Government of Kenya. (2011). Strategy for Tsetse and Trypanosomiasis eradication in Kenya 2011-2021. Ministry of Livestock Development. Nairobi.

Green, P. E., \& Srinivasan, V. (1990). Conjoint analysis in marketing: New developments with implications for research and practice. Journal of Marketing, 4, 3-19.

Green, P., \& Srinivasan, V. (1990). Conjoint analysis in marketing: New developments with implications for research and practice. Journal of Marketing, 54, 3-19.

Greene, W. H. (1990). Econometric analysis. MacMillan Publishing Co., New York, 783.

Griliches, Z. (1971). Price Indexes and Quality Change. Cambridge: Harvard University Press.

Hubbard, M. (1997). The new institutional economics in agricultural development: insights and challenges. Journal of Agricultural Economics, 48, 239-249

ILRAD. (1994). Annual Reports. Nairobi.

Jaetzold, R., \& Schmidt, H. (1983). Farm management handbook of Kenya. Volume IIC: East Kenya (Eastern and Coast Provinces). Farm Management Branch, Ministry of Agriculture, Nairobi, Kenya.

Kerlinger, F. N. (2003). Foundations of Behavioral Research (2nd ed.). New York: Holt Rinehart and Wilson, Inc.

Kothari, G. R. (2009). Research Methodology. New Delhi: Vrinda Publishing company.

Lancaster, K. J. (1966). New Approach to Consumer Theory. Journal of Political Economy, 74, 132-157.

Lancaster, K. J. (1991). Modern Consumer Theory. Edward Elgar Publishing Ltd, England.

Leedy, P. (2005). Practical Research Planning and design (6th ed.). Columbus.

Louviere J. J. (1994). Conjoint analysis. In R. P. Bagozzi (ed.), Advanced Methods of Market Research. Blacwell Business, Massachusetts and Oxford.

Nabli, M. K., \& Nugent, J. B. (1989). The New Institutional Economics and its applicability to development. World Development, 17, 1333-1347.

Oruko, L. O. (1999). Delivery of animal health services in Kenya. Ph.D. Thesis. Department of Agricultural and Food Economics, University of Reading, Reading, UK

Randolph, T., \& Ndung'u, L. (2000). Gender and transaction cost: A conjoint analysis of choice of livestock health service among smallholder dairy farmers in Kenya. Background paper for poster presented at the $X_{X I V}{ }^{\text {th }}$ Congress of the IAAE Berlin, 18-24 August 2000.

Rosen, S. (1974). Hedonic prices and implicit markets: Product differentiation in pure competition. Journal of Political Economics, 82, 34-55.

Saunders, M., Lewis, P., \& Thornhill, A. (2007). Research methods for business for Students (4th ed.). Pearson Education Limited Artes Graficas.

Staal, S. J., Chege, L., Kenyanjui, M., Kimari, A., Lukuyu, B., Njubi, D., ... Wambugu, M. (1997). Characterization of dairy systems supplying the Nairobi milk market. A pilot survey in Kiambu District for the identification of target groups and producers. May 1997.

Staal, S. J., Delgado, C., \& Nicholson, C. (1997). Smallholder dairying under transaction costs in East Africa. World Development, 25, 779-794.

Woods, P. S. (2000). The importance of proximity, transport and gender as transaction costs in the use of veterinary services in Zimbabwe. In D. K. Leonard (ed.), Africa's changing markets for health and veterinary services: The New Institutional Issues (pp. 67-92). New York: St. Martin's Press Inc.. 
Appendix I. Tsetse Distribution in Kenya

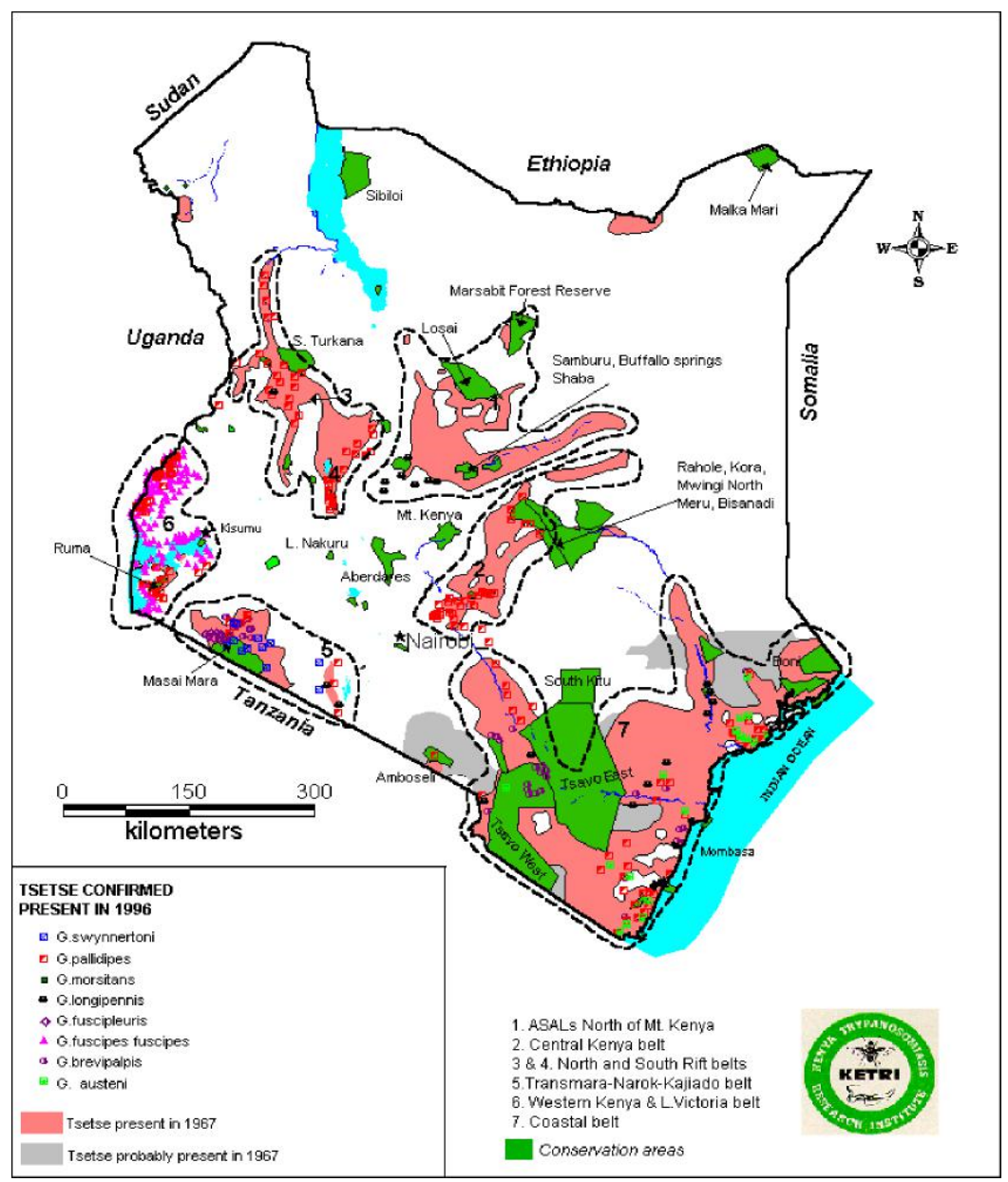

Figure 1. Tsetse Distribution in Kenya

Appendix II: Location of Busia County

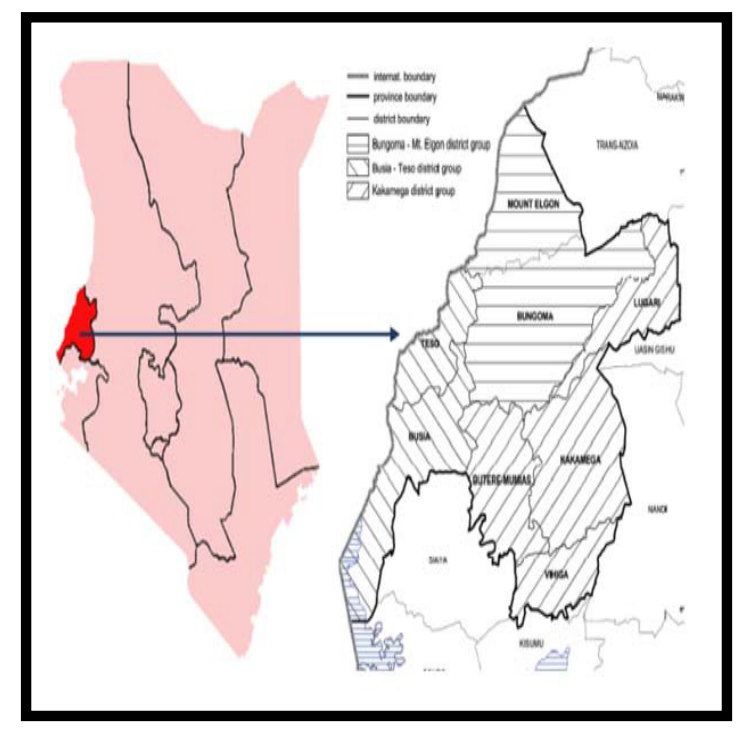

Figure 2. Location of Busia County

Source: Jaetzold and Schmidt, 1983. 
Appendix III: Card List Zero Grazing Net

\begin{tabular}{rllll}
\hline Card ID & Cost for net/cow/year & \multicolumn{1}{c}{ Source of net } & Lifespan of net & Retreatment of net with insecticide \\
\hline 1 & Low ksh 800 & Near less than $25 \mathrm{~km}$ & Over 3 years & Not retreatable \\
2 & Medium ksh 1600 & Near less than $25 \mathrm{~km}$ & One year & Not retreatable \\
3 & Low ksh 800 & Far beyond $100 \mathrm{~km}$ & Two years & Not retreatable \\
4 & Low ksh 800 & Near less than $25 \mathrm{~km}$ & Two years & Not retreatable \\
5 & Low ksh 800 & Near less than $25 \mathrm{~km}$ & Two years & Retreatable \\
6 & High ksh 2400 & Far beyond $100 \mathrm{~km}$ & Two years & Not retreatable \\
7 & High ksh 2400 & Near less than $25 \mathrm{~km}$ & One year & Retreatable \\
8 & Medium ksh 1600 & Far beyond $100 \mathrm{~km}$ & One year & Retreatable \\
9 & Medium ksh 1600 & Far beyond $100 \mathrm{~km}$ & Over 3 years & Retreatable \\
10 & Low ksh 800 & Far beyond $100 \mathrm{~km}$ & One year & Retreatable \\
11 & Low ksh 800 & Far beyond $100 \mathrm{~km}$ & One year & Not retreatable \\
12 & Medium ksh 1600 & Near less than $25 \mathrm{~km}$ & Two years & Retreatable \\
13 & Low ksh 800 & Far beyond $100 \mathrm{~km}$ & Two years & Retreatable \\
14 & High ksh 2400 & Near less than $25 \mathrm{~km}$ & Over 3 years & Not retreatable \\
15 & Low ksh 800 & Near less than $25 \mathrm{~km}$ & One year & Not retreatable \\
16 & Low ksh 800 & Near less than $25 \mathrm{~km}$ & One year & Retreatable \\
17 & Medium ksh 1600 & Far beyond $100 \mathrm{~km}$ & One year & Not retreatable \\
18 & High ksh 2400 & Far beyond $100 \mathrm{~km}$ & One year & Retreatable \\
19 & High ksh 2400 & Near less than $25 \mathrm{~km}$ & Two years & Not retreatable \\
20 & Low ksh 800 & Far beyond $100 \mathrm{~km}$ & Over 3 years & Retreatable \\
\hline
\end{tabular}

a. Holdout.

Appendix VI: Sample Card for Zero Grazing Net

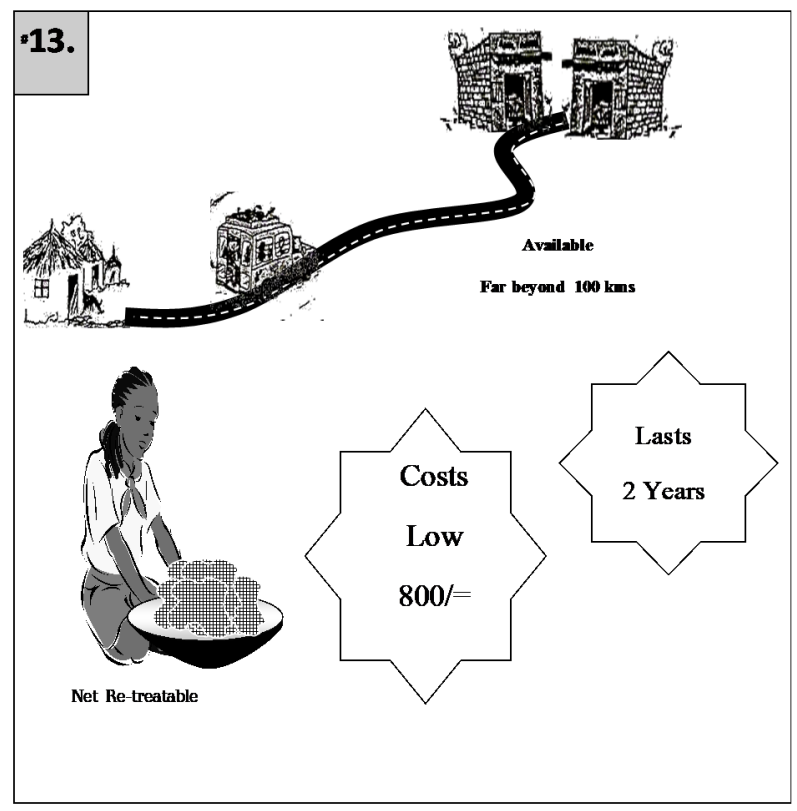

Figure 3.1 Map of Busia County

Source: Jaetzold et al., 2005: Farm Management Handbook of Kenya, Vol.II. Western Pro.

\section{Copyrights}

Copyright for this article is retained by the author(s), with first publication rights granted to the journal.

This is an open-access article distributed under the terms and conditions of the Creative Commons Attribution license (http://creativecommons.org/licenses/by/4.0/). 